\title{
Effect of Acupressure of Xue Hai Point on Severity of Pain in Primary Dysmenorrhea
}

\author{
Ezadi H. ${ }^{1}$ MSc, Geranmay M.* MSc, Taebi N.S. ${ }^{2}$ MSc
}

\begin{abstract}
*Midwifery Department, Nursing \& Midwifery Faculty, Iran University of Medical Sciences, Tehran, Iran
${ }^{1}$ Midwifery Department, Nursing \& Midwifery Faculty, Iran University of Medical Sciences, Tehran, Iran 2Midwifery Department, Health Faculty, Berlin University of Medical Sciences, Berlin, Germany
\end{abstract}

\begin{abstract}
Aims: There is a prevalence of dysmenorrhea in women. The treatment of the disease includes medication and non-medication treatments. The nonmedication treatments, such as acupressure, are recently noticed by the patients. The aim of this study was to investigate the effects of pressure on the tenth spleen point on the pain severity in the primary dysmenorrhea.

Materials \& Methods: In this one-blind random clinical trial, 100 female students with primary dysmenorrhea, who were residents of the dormitories of Tehran University of Medical Sciences, were studied in 2012. The subjects, selected via purposeful sampling method, were divided into control $(n=50)$ and intervention $(n=50)$ groups based on the randomization program. Data was collected by a demographic questionnaire, the pain ruler, and the visual scale. The pressure medicine and its application, the tenth spleen point, way to find the point, and its massage method were trained in intervention group. There was no intervention in control group. The pain severity was measured before the intervention and one, two, and three months after it. Data was analyzed by SPSS 16 software using Chi-square and independent T tests.

Findings: There was no significant difference between control and intervention groups in mean pain severity $(\mathrm{p}=0.143)$. Therefore, the groups were the same in the pain severity. There were significant differences in the first, the second, and the third months after the intervention between the groups. In addition, there was a reduction in pain severity after 3 months in intervention group $(\mathrm{p}<0.001)$.

Conclusion: Pressure on the tenth spleen point is effective on the reduction of pain severity in the primary dysmenorrhea.
\end{abstract}

\section{Keywords}

Dysmenorrhea [http://www.ncbi.nlm.nih.gov/mesh/68004412];

Acupressure [http://www.ncbi.nlm.nih.gov/mesh/68019050];

Tenth Spleen (Xue Hai) Point [Not in MeSH]

\author{
* Corresponding Author \\ Tel: +98 (21) 66937120 \\ Fax: +98 (21) 66904252 \\ Address: Nursing \& Midwifery Faculty, East Nosrat Street, Tohid Square, Tehran, Iran. Post Code: 1419733171 \\ geranmay@tums.ac.ir \\ Received: April 3, 2015


معمولاً محدود به قسمت تحتانى شكم بوده، در خط وسط از

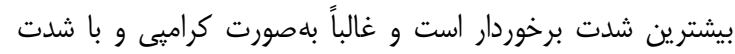

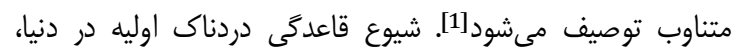

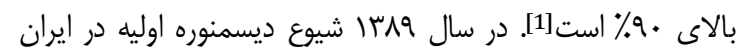

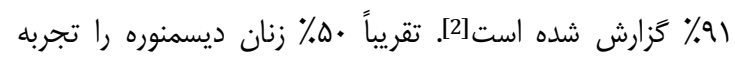

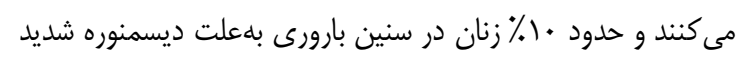

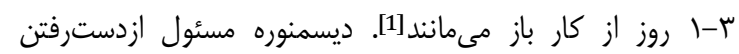

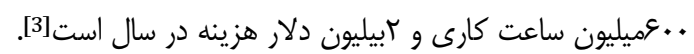

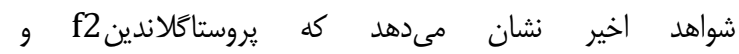

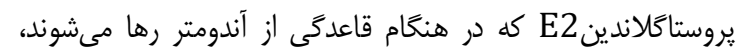

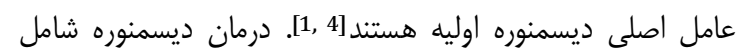

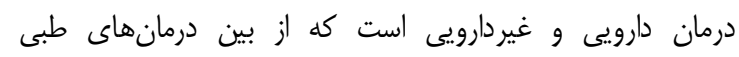

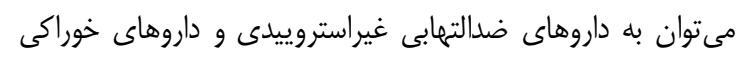

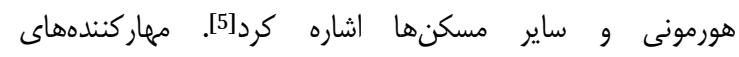

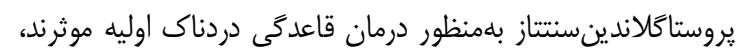

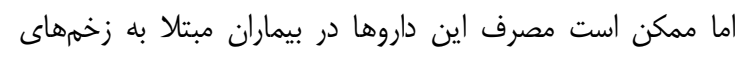

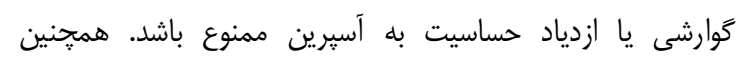

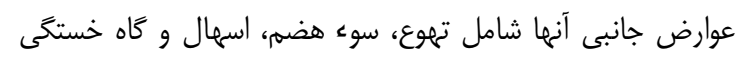

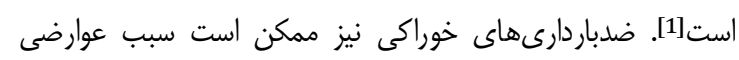

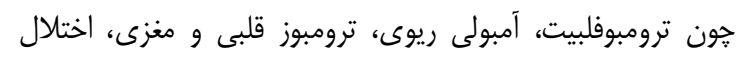

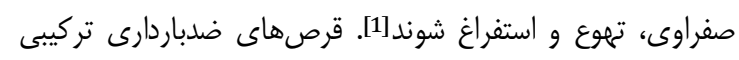

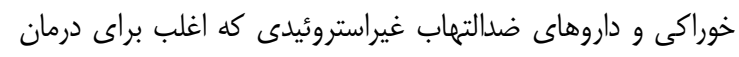

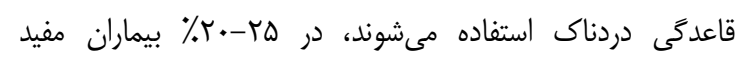

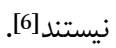

در سالهاى اخير روشهاى غيردارويى، توجه كليه بيماران را به تهان

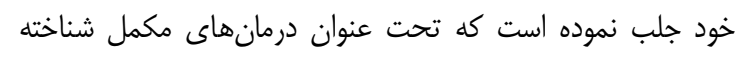

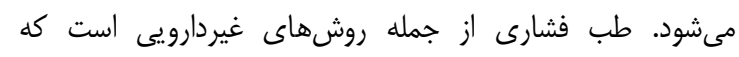

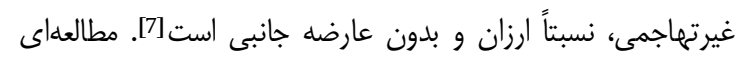

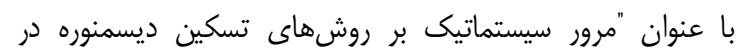

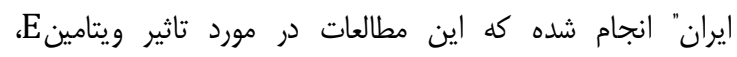

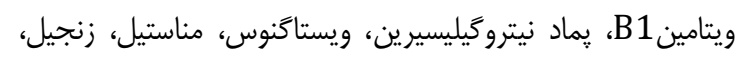

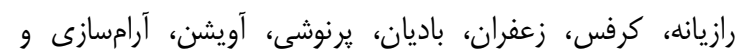

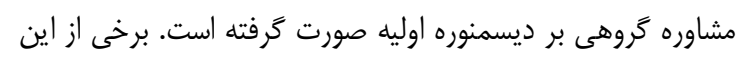

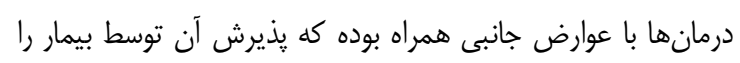

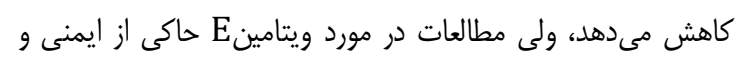

$$
\text { كار آيى آن است م6ى]. }
$$

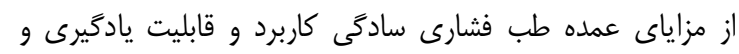

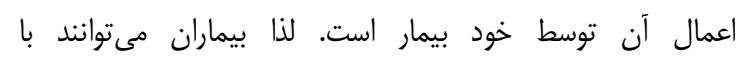

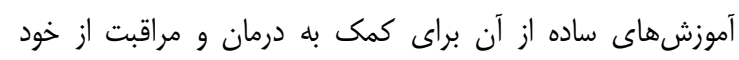

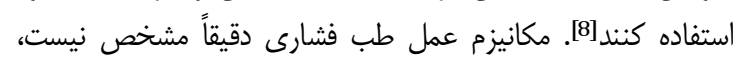

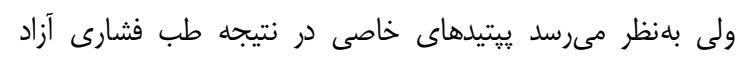

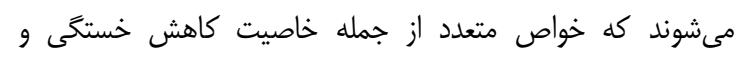

\section{تاثير طب فثارى نقطه دهم طحالى بر ميزان شدت درد قاعدكى زنان}

حميده ايزدى MSc كروه مامايى، دانشكده يرستارى و مامايى، دانشخاه علوم يزشكى ايران، تهران، ايران

\section{MSc مهرناز ترانماية}

گروه مامايى، دانشكده يرستارى و مامايى، دانشخاه علوم يزشكى ايران، تهران،

ايران

MSc نسيم السادات طيبى

كروه مامايى، دانشكده بهداشت، دانشخاه علوم يزشكى برلين، برلين، آلمان

جكيده

اهداف: ديسمنوره در زنان از شيوع بالايى برخوردار است. درمان

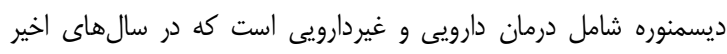

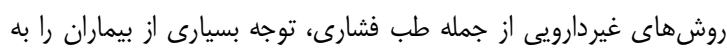

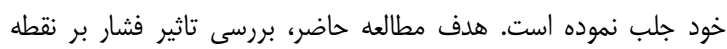

دهم طحالى بر شدت درد در ديسمنوره اوليه بود.

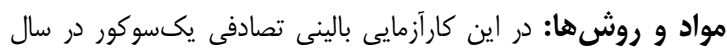

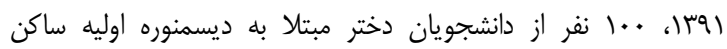

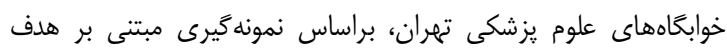

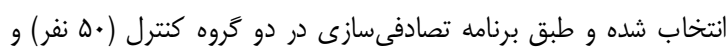

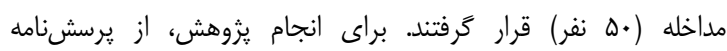

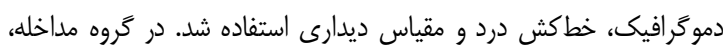

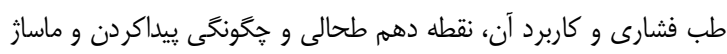

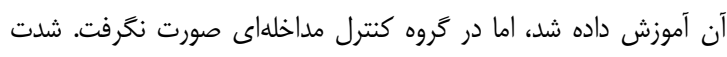

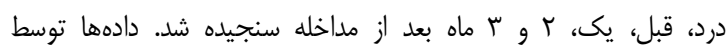

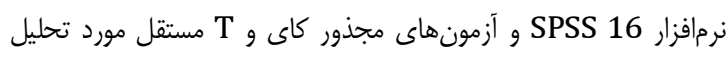

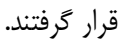

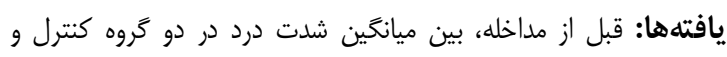

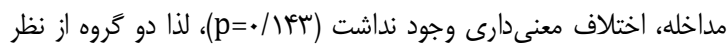

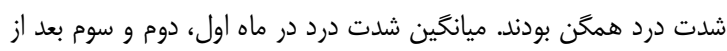

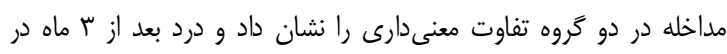

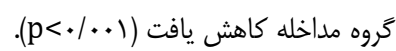

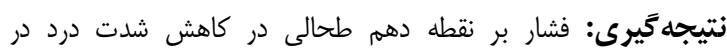

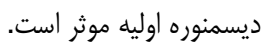
كليدوازهها: ديسمنوره، طب فشارى، نقطه دهم طحالى ألى

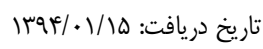

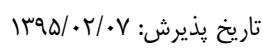
"نويسنده مسئول: geranmay@tums.ac.ir

مقدمه

در ديسمنوره يا قاعدگى دردناك اوليه، درد مشخصاً همگام با شروع

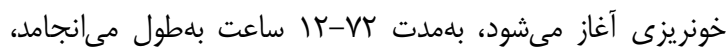

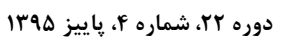

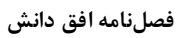




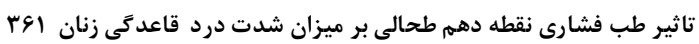

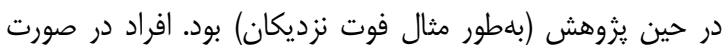

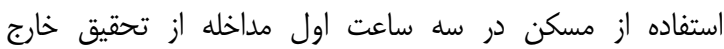

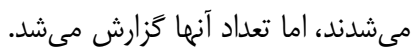

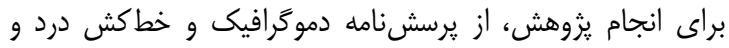

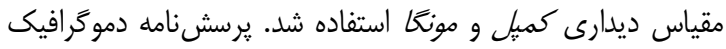

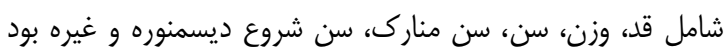

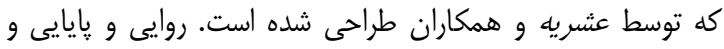

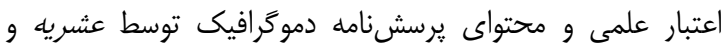

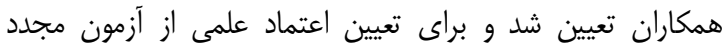

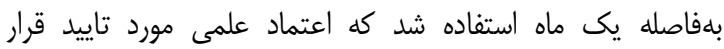

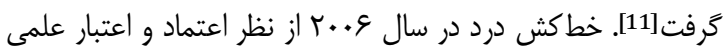

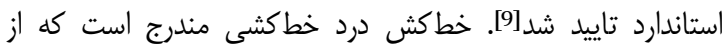

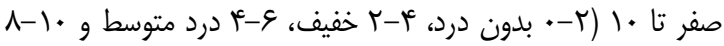
درد شديد) شمارهكذارى شده است.

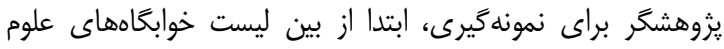

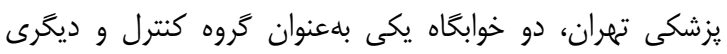

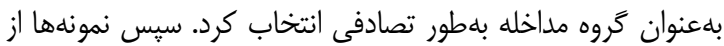

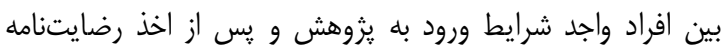

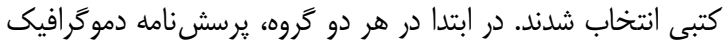
بلهنظور تعيين اينكه اين افراد دهار ديسمنوره اوليه هستند تكميل

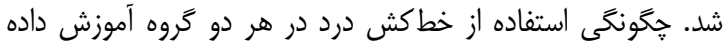

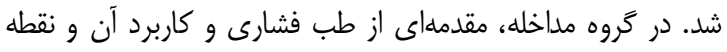

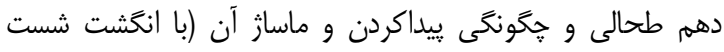

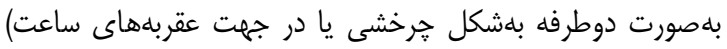

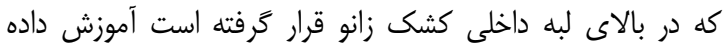

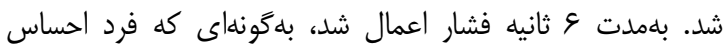

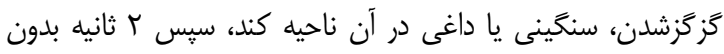

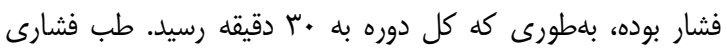
توسط فرد متخصص، آموزش داده شد. با شروع دوره تا بّ روز اول درل

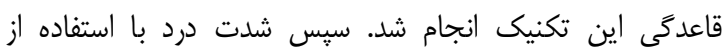

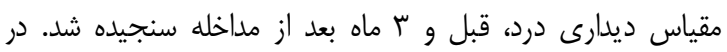

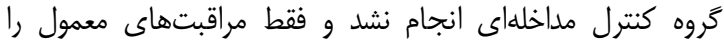

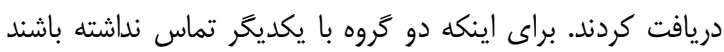

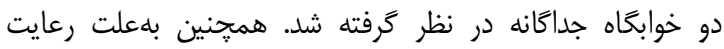

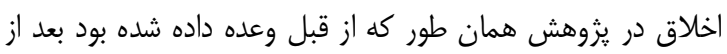

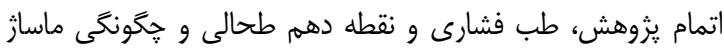
در كروه كنترل نيز آموزش داده شد.

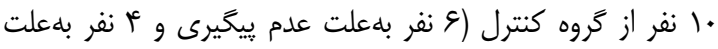

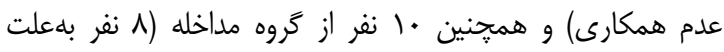

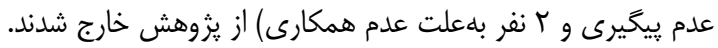

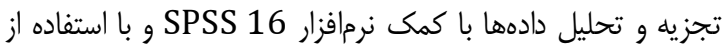

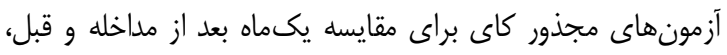

ضددردى دارند. اين يِيتيدها تا حدودى مكانيزم ضددردى طب

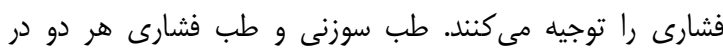

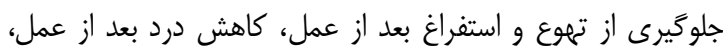

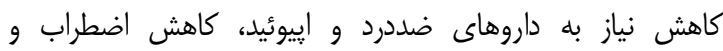

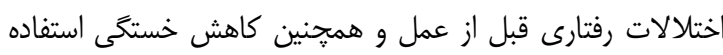

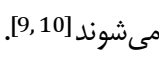
نقطه دهم طحالى هنگامى كه زانو بلهصورت خمشانده قرار دارد در

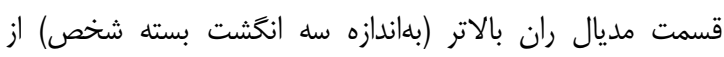

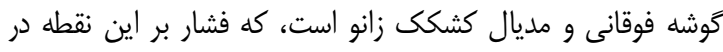

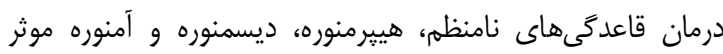

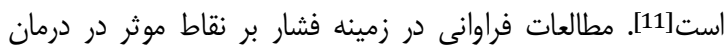

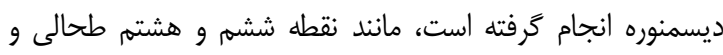

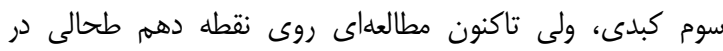

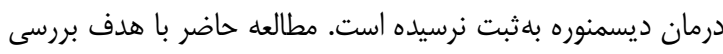
تاثير فشار بر نقطه دهم طحالى بر شدت درد در ديسمنوره اوليه

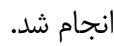

\section{مواد و روشها}

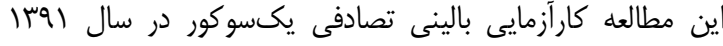

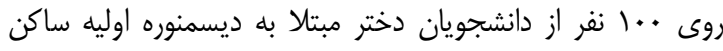

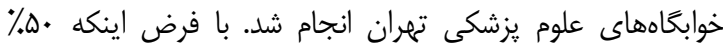

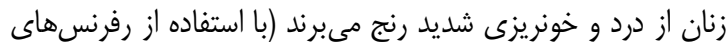

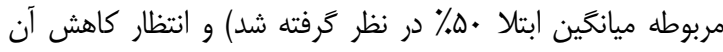

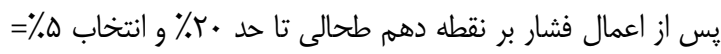

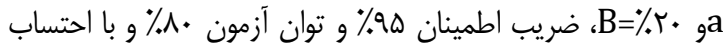

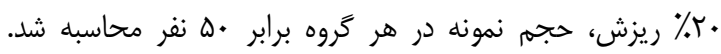

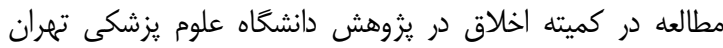

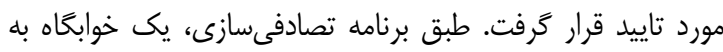

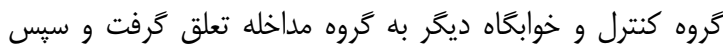
براساس نمونهَّيرى مبتنى بر هدف نمونههاى واجد شرايط انتخاب شدند.

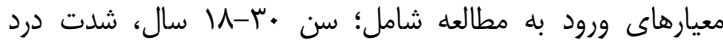

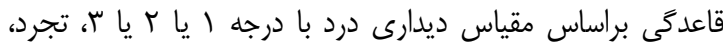

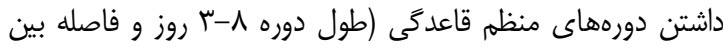

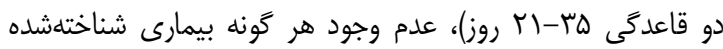

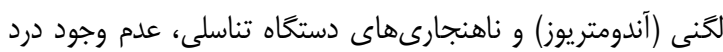

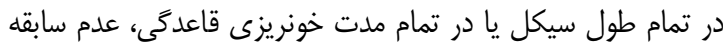

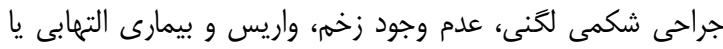

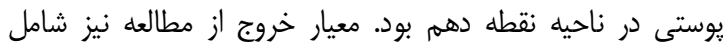

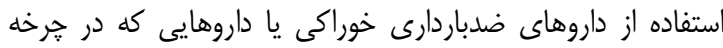

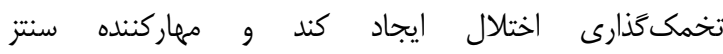
يروستاكًاندينها در حين يزوهش و وجود استرس هاى شديد روانى 
نتايج اين مطالعه نشان داد كه فشار بر نقطه دهم طحالى در حين

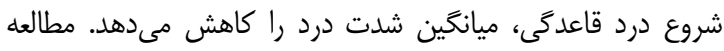
مرورى با هدف تاثير طب فشارى بر ديسمنوره اوليه در جين انجام

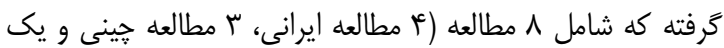

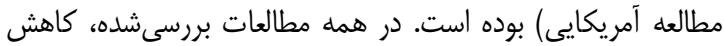
شدت درد قاعدگى مشاهده شده و هيج عارضه جانبى ايجاد نشده دها است. نتايج مطالعه فوق با مطالعه حاضر منطبق است [12]. همجنين إنين

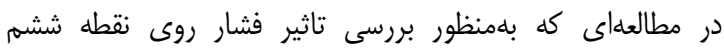
طحالى بر شدت درد قاعدگى دردناى اوليه در دانشجويان دختر

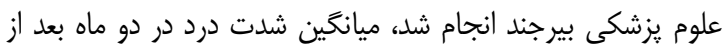

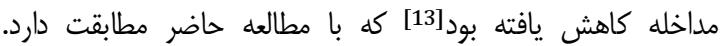
مقايسه هر دو مطالعه نشان داد، هر دو داراى ابزار و روش كار يكسان هستند.

در مطالعه در مورد تاثير طب سوزنى بر ديسمنوره اوليه مشخص شد، يكى از علتهاى تاثير طب سوزنى در درمان ديسمنوره برطرفكردن ايستايى خون است كه با طب سوزنى بر نقطه دهم

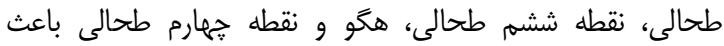

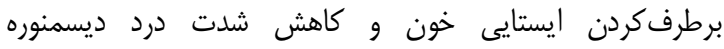

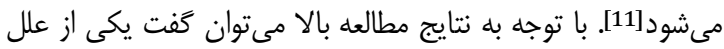

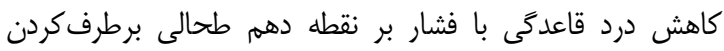
ايستايى خون است. در مطالعهاى كه اثر طب فشارى بر درد قاعدگى را بررسى كرده است در روز اول شدت درد كاهش

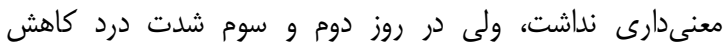

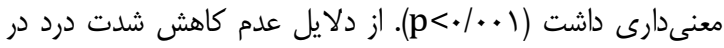
روز اول اين است كه طب فشارى نسبت به درمانهاى دارويى تاثير

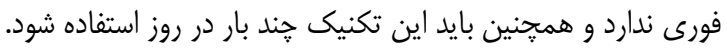
در اين مطالعه فشار بر نقطه ششم طحالى باعث كاهش داهن درد قاعدكى شده[14] كه با نتيجه مطالعه يزوهشگر همخرانى دارد. مطالعهاى مرورى در زمينه تاثير طب فشارى و سوزنى بر نقطه ماره ششم طحالى در درمان ديسمنوره اوليه انجام شده است. اين مطالعه

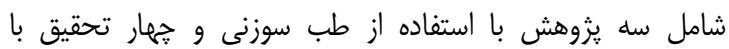

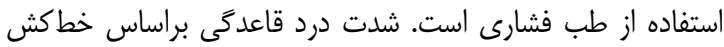

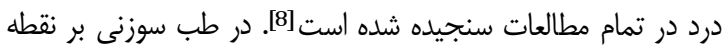
ششم طحالى، شدت درد بين گروه مداخله و كنترل تفاوت

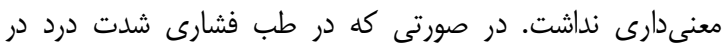
گروه فشار بر نقطه ششم طحالى و كنترل (استراحت، يلاسبو)

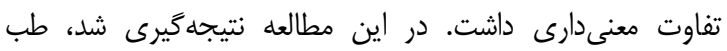
فشارى بر نقطه ششم طحالى موثرتر از طب سوزنى در ديسمنوره اوليه است. در اين مطالعه، طب فشارى بلهعنوان وسيلهاى موثرتر از

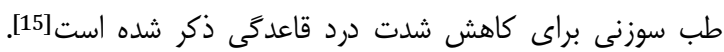

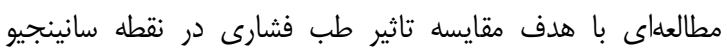

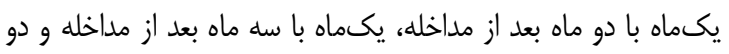

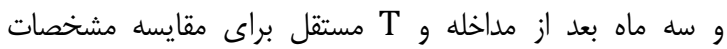

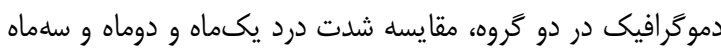
قبل و بعد از مداخله انجام شد.

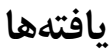

بين دو گروه كنترل و مداخله از نظر متغيرهاى جمعيتشناختى و مارها

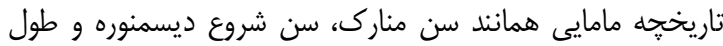

مدت قاعدگى تفاوت آمارى معنى دارى وجود نداشت (جدول () منائل

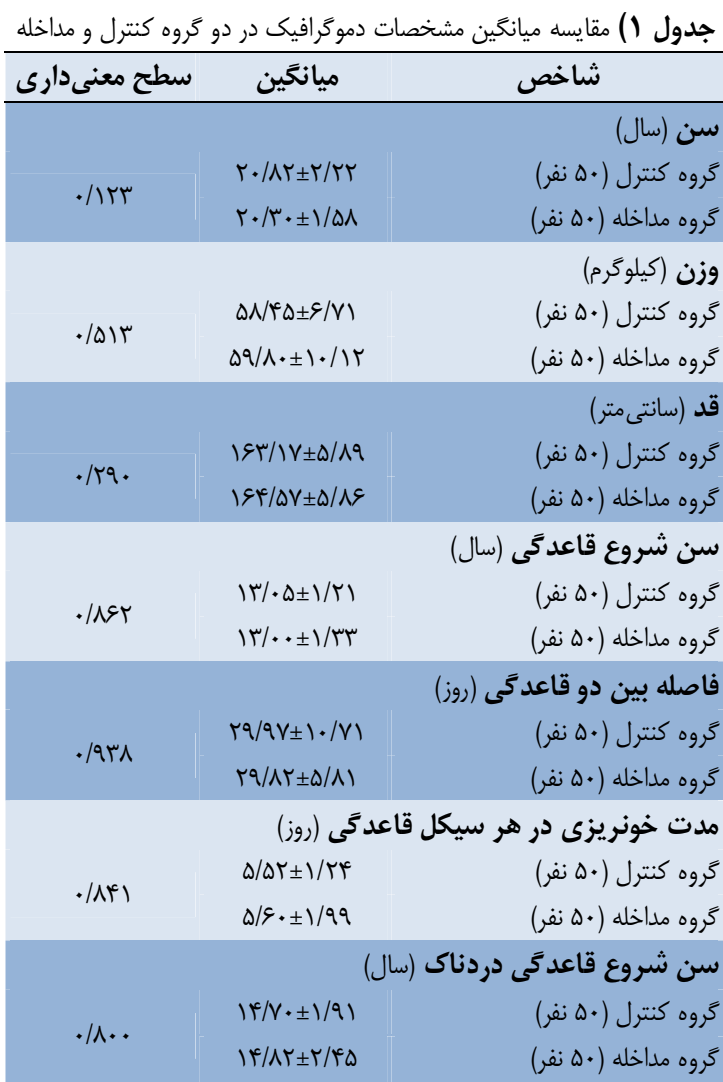

بين ميانكَين شدت درد در دو كَروه كنترل و مداخله، قبل از مداخله

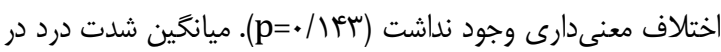

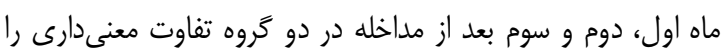

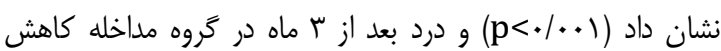

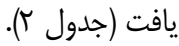

جدول r) مقايسه ميانكين آمارى شدت درد قبل و ا، r و r ماه بعد از مداخله

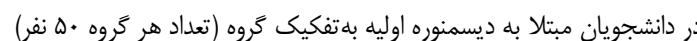

\begin{tabular}{|c|c|c|}
\hline تروه مداخله & كروه كنترل & مرحله \\
\hline g/rTII/Ar & $\Delta / V V \pm I / \uparrow \wedge$ & قبل از مداخله \\
\hline$r / \Delta \xi \pm r / \mu r$ & $\Delta / 9 \Delta \pm 1 / \Delta \Delta$ & ا ماه بعد از مداخله \\
\hline$r / r q \pm r / 4 q$ & $g / \cdot r \pm 1 / r r$ & r ماه بعد از مداخله \\
\hline$r / q r \pm r / \Delta q$ & $8 / 1 \cdot \pm 1 / \Delta r$ & سّ ماه بعد از مداخله \\
\hline
\end{tabular}

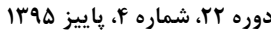

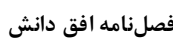




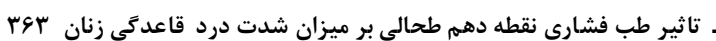
2- Molazem Z, Alhani F, Anooshe M, Vagharseyyedin A. Epidemiology of dysmenorrhea with dietary habits and exercise. Zahedan J Res Med Sci. 2011;13(3):47-51. [Persian]

3- French L. Dysmenorrhea. Am Fam Physician. 2005;71(2):285-91.

4- Fritz MA, Speroff L. Clinical gynecologic endocrinology and infertility [Volume 1]. 18 $8^{\text {th }}$ edition. London: Lippincott Williams \& Wilkins; 2010. p.p. 471-2.

5- Ou MC, Hsu TF, Lai AC, Lin YT, Lin CC. Pain relief assessment by aromatic essential oil massage on outpatients with primary dysmenorrheal: A randomized, double- blind clinical trial. J Obstet Gynaecol Res. 2012;38(5):817-22.

6- Damghanian M, Mortazavi F. The management for primary dysmenorrhea in Iran: A systematic review [Dissertation]. Mashad: Mashhad University of Medical Sciences; 2012. [Persian]

7- Lee EJ, Frazier SK. The efficacy of acupressure for symptom management: A systematic review. J Pain Symptom Manage. 2011;42(4):589-603.

8- Teplitz JV. Migraine management. Occup Health Saf. 2004;73(10):20-1.

9- Chen MN, Chien LW, Liu CF. Acupuncture or acupressure at the sanyinjiao (SP6) acupointfor the treatment of primary dysmenorrhea: A meta-analysis. Evid Based Complement Altern Med. 2013;2013:1-8.

10- Gharloghi S, Torkzahrani S, Akbarzadeh AR, Heshmat R. The effects of acupressure on severity of primary dysmenorrhea. Patient Prefer Adherence. 2012;6:13742.

11- Smith CA, Crowther CA. Petrucco O, Beilby J, Dent H. Acupuncture to treat primary dysmenorrhea in women: A randomized controlled trial. Evid Based Complement Altern Med. 2011;2011:1-11.

12- Wang YJ, Hsu CC, Yeh ML, Lin JG. Auricular acupressure to improve menstrual pain and menstrual distress and heart rate variability for primary dysmenorrhea in youth with stress. Evid Based Complement Altern Med. 2013;2013:1-8.

13- Rakhshekhorshid M, Foadoddini M, Saadatjoo SA. Comparison between the effects of applying massage and ice massage to SP6(SPLEEN6) point on severity and length of primary dysmenorrhea. J Birjand Univ Med Sci. 2013;20(1):11-9. [Persian]

14- Bazarganipour F, Lamyian M, Heshmat R, Abadi MA, Taghavi A. A randomized clinical trial of the efficacy of applying a simple acupressure protocol to the Taichong point in relieving dysmenorrhea. Int J Gynaecol Obstet. 2010;111(2):105-9.

15- Kashefi F, Ziyadlou S, Khajehei M, Ashraf AR, Fadaee AR, Jafari P. Effect of acupressure at the Sanyinjiao point on primary dysmenorrhea: A randomized controlled trial. Complement Ther Clin Pract. 2010;16(4):198-202.

16- Jiang H, Ni Sh, Li J, Liu M, Li J, Cui X, et al. systematic review of randomized clinical trials of acupressure therapy for prim dysmenorrhea. Evid Based Complement Altern Med. 2013;2013:1-9.

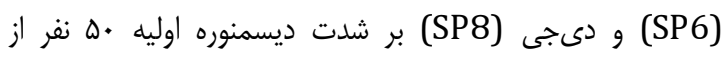

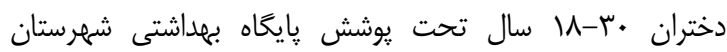

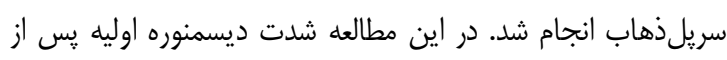

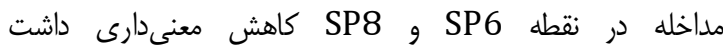

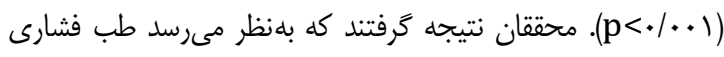

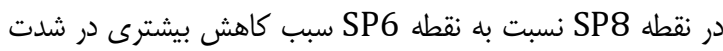

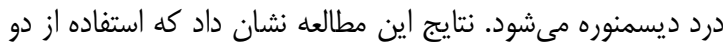

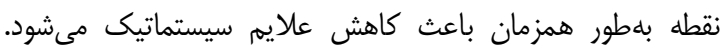

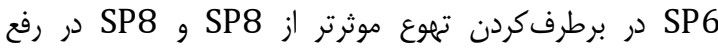

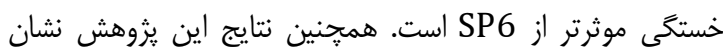

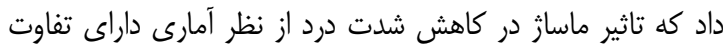

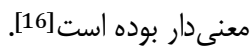

$$
\begin{aligned}
& \text { از محدوديتهاى خارج از كنترل اين يُوهش، اعتماد به كَفتههاى }
\end{aligned}
$$

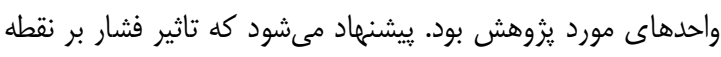

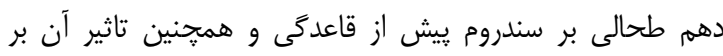

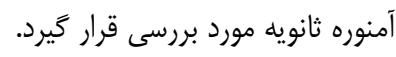

$$
\begin{aligned}
& \text { نتيجه كَيرى } \\
& \text { فشار بر نقطه دهم طحالى در كاهش شدت درد در ديسمنوره اوليه }
\end{aligned}
$$

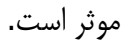$$
\text { تشكر و قدردانى: مجريان اين يزوهش از معاونت دانشخاه علوم }
$$

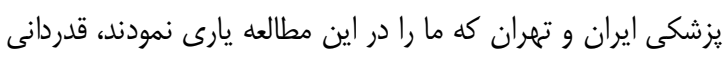

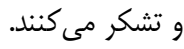$$
\text { تاييديه اخلاقى: اين مطالعه بخشى ازئل إياياننامه دوره }
$$

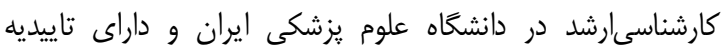$$
\text { كميته اخلاق بلشماره كارش }
$$

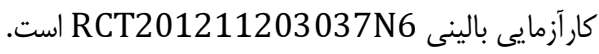$$
\text { تعارض منافع: نويسندكان مقاله اعلام مى كنند كه هيج كونه }
$$$$
\text { تعارض منافعى وجود ندارد. }
$$

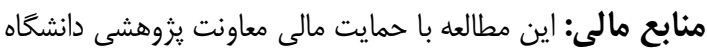$$
\text { علوم يزشكى ايران انجام شده است. }
$$$$
\text { منابع }
$$

1- Berek JS. Berek and Novak's gynecology. In: Deborah L, Berek MA, editors. Textbook of gynecology. London: Lippincott Williams \& Wilkins; 2012. pp. 390-413. 